\title{
Post-concussion symptoms in sports-related mild traumatic brain injury compared to non-sports-related mild traumatic brain injury
}

\author{
Frédérique Beauchamp ${ }^{1,2,3}$. Valérie Boucher ${ }^{1,2} \cdot$ Xavier Neveu $^{1,2} \cdot$ Vincent Ouellet ${ }^{1,2,3}$. Patrick Archambault ${ }^{3,4}$. \\ Simon Berthelot ${ }^{1,2,3}$. Jean-Marc Chauny ${ }^{5}$. Elaine de Guise ${ }^{5,6,7} \cdot$ Marcel Émond $^{1,2,3}$. Jérôme Frenette ${ }^{2}$. Eddy Lang ${ }^{8}$. \\ Jacques Lee ${ }^{9}$ Éric Mercier ${ }^{1,2,3} \cdot$ Lynne Moore $^{2,3,10} \cdot$ Marie-Christine Ouellet $^{3,11} \cdot$ Jeffrey Perry ${ }^{12} \cdot$ Natalie Le Sage $^{1,2,3}$
}

Received: 3 June 2020 / Accepted: 27 November 2020 / Published online: 29 January 2021

(c) Canadian Association of Emergency Physicians (CAEP)/ Association Canadienne de Médecine d'Urgence (ACMU) 2021

\begin{abstract}
Objectives To compare post-concussion symptoms in patients who sustained a sports-related mild traumatic brain injury (TBI) to those with non-sports-related mild TBI at 7 and 90 days post-injury.

Methods This prospective multicentre cohort study took place in seven Canadian Emergency Departments (ED). Nonhospitalized patients aged $\geq 14$ years with a documented mild TBI that occurred $\leq 24 \mathrm{~h}$ of ED visit and a Glasgow Coma Scale score $\geq 13$ were included. Main outcome measure was the presence of $\geq 3$ symptoms on the Rivermead Post-concussion Questionnaire at 90 days post-injury. Secondary outcomes were the prevalence of (1) individual Rivermead Post-concussion Questionnaire symptom, (2) total Rivermead Post-concussion Questionnaire score $\geq 21$ and (3) return to normal daily activities. Adjusted risk ratios (RR) were calculated.

Results 1727 patients were included, 363 (21.0\%) sustained a sports-related mild TBI. Similar proportions of patients with $\geq 3$ symptoms, a Rivermead Post-concussion Questionnaire score $\geq 21$ and those who returned to their normal daily activities were observed at 7 and 90 days post-injury. Sports-related mild TBI patients were at higher risk of poor concentration [RR: 1.3 (95\% CI 1.05-1.54)] and non-return to sports activities [RR: 2.2 (95\% CI 1.69-2.94)] at 7 days post-injury. At 90 days, sports-relate -mild TBI patients reported less fatigue [RR: 0.7 (95\% CI 0.51-0.98)] and feeling of dizziness [RR: 0.6 (95\% CI 0.35-0.99)].

Conclusion Patients who sustained sports-related mild TBI could be at lower risk of experiencing symptoms such as fatigue and dizziness 90 days post-injury. Clinicians should be mindful that non-sports-related mild TBI patients may experience more post-concussion symptoms and that the level of physical activity may influence the patient's rehabilitation.
\end{abstract}

Keywords Brain injury $\cdot$ Post-concussion symptoms $\cdot$ Sports $\cdot$ Mild traumatic brain injury $\cdot$ Sports-related mild traumatic brain injury

Natalie Le Sage

natalie.lesage@fmed.ulaval.ca

1 Population Health and Optimal Health Practices Research Unit, Trauma, Emergency, Critical Care Medicine, CHU de Québec-Université Laval Research Centre, Hôpital de l'Enfant-Jésus, 1401, 18e rue, H-610, Québec, QC G1J 1Z4, Canada

2 Centre de Recherche sur les Soins et les Services de Première Ligne de l'Université Laval (CERSSPL-UL), Quebec City, Canada

3 Faculté de Médecine, Université Laval, Quebec City, Canada

4 Centre Intégré de Santé et de Services Sociaux de ChaudièreAppalaches, Centre Hospitalier Affilié Universitaire HôtelDieu de Lévis, Lévis, Canada

5 Université de Montréal, Montreal, Canada
6 Research-Institute, McGill University Health Centre, Montreal, Canada

7 Centre de Recherche Interdisciplinaire en Réadaptation du Montréal Métropolitain (CRIR), Montreal, Canada

8 University of Calgary, Calgary, Canada

9 Schwartz/Reisman Emergency Medicine Institute, Toronto, Canada

10 Department of Social and Preventative Medicine, Université Laval, Québec, QC, Canada

11 Centre Interdisciplinaire de Recherche en Réadaptation et Intégration Sociale (Cirris), Québec, QC, Canada

12 Ottawa Hospital Research Institute and Department of Emergency Medicine, University of Ottawa, Ottawa, Canada 


\section{Résumé}

Objectifs Comparer les symptômes post-commotionnels chez les patients ayant subi un traumatisme cranio-cérébral léger (TCCL) lié au sport à ceux qui ont un TCCL non lié au sport à 7 et 90 jours post-traumatisme.

Méthodes Cette étude prospective de cohorte multicentrique s'est déroulée dans sept Départements d'urgence (DU) du Canada. Les patients non hospitalisés âgés de $\geq 14$ ans ayant subi un TCCL $\leq 24$ heures avant leur visite au DU et présentant un score de Glasgow de $\geq 13$ ont été inclus. Le critère principal de jugement était la présence d'au moins 3 symptômes au Rivermead Post-concussion Questionnaire 90 jours après le traumatisme. Les critères de jugement secondaires étaient la prévalence de 1) chacun des symptômes du Rivermead Post-concussion Questionnaire 2) score total du Rivermead Postconcussion Questionnaire $\geq 21$ et 3 ) retour aux activités habituelles. Des risques relatifs ajustés (RR) ont été calculés.

Résultats Un total de 1727 patients a été inclu, dont 363 (21,0\%) ont subi un TCCL lié au sport. Des proportions similaires de patients présentant $\geq 3$ symptômes, un score $\geq 21$ au Rivermead Post-concussion Questionnaire et de participants ayant repris leurs activités habituelles ont été observés à 7 et 90 jours après la blessure. Les patients avec TCCL lié au sport présentaient un risque plus élevé de manque de concentration (RR: 1,3 [IC à $95 \%=1,05-1,54]$ ) et de non-retour aux activités sportives (RR: 2,2 [IC à $95 \%=1,69-2,94]$ ) à 7 jours après la blessure. À 90 jours, les patients avec TCCL lié au sport ont signalé moins de fatigue (RR: 0,7 [IC à $95 \%=0,51-0,98]$ ) et de sensation de vertige (RR: 0,6 [IC à 95\%=0,35-0,99]).

Conclusion Les patients qui ont subi un TCCL lié au sport seraient moins à risque de présenter des symptômes tels que de la fatigue et des étourdissements 90 jours après la blessure. Les cliniciens doivent être conscients que les patients avec TCCL non lié au sport peuvent présenter davantage de symptômes post-commotionnels et que le niveau d'activité physique peut influencer la réadaptation du patient.

\section{Clinician's capsule}

\section{What is known about the topic?}

Little is known about the impact of sports injury compared to non-sports injury, on mild Traumatic Brain Injuries (TBI) recovery.

\section{What did this study ask?}

To compare post-concussion symptoms in patients who sustained a sports-related mild TBI to those with non-sports-related mild TBI.

\section{What did this study find?}

Patients who sustained sports-related-mild TBI are at lower risk of experiencing symptoms such as fatigue and dizziness 90 days post-injury.

\section{Why does this study matter to clinicians?}

Clinicians should be mindful that non-sports-relatedmild TBI patients may experience more post-concussion symptoms and physical activity level may influence rehabilitation.

\section{Introduction}

In 2013, traumatic brain injuries (TBI) led to approximately 2.8 million emergency department (ED) visits, hospitalizations and deaths in United States [1]. Mild TBI, or concussion, is the most common type of TBI [2] and must, therefore, be considered a serious public health issue. One

Canadian study estimated that the incidence of hospitaltreated mild TBI in Ontario was at least 493 per 100,000 patients [3]. Although this type of trauma can be the result of a wide variety of mechanisms, $54 \%$ are sport-related in patients aged 16-34 years according to The Canadian National Health Population Survey [4]. Sports-related mild TBI are defined in the literature as a mild TBI that was induced by biomechanical forces during recreational or high-level sports practice [5]. It is estimated that 1.6-3.8 million sports-related TBI (which includes mild TBI) occur each year in the United States [6].

There are numerous available studies regarding mild TBI pathophysiology [7], diagnosis $[5,8]$, treatments $[5,9,10]$, predictors of wellness [11, 12] and symptom evolution [13]. Since about $24 \%$ of mild TBI patients remain significantly impaired by persistent symptoms such as headaches, dizziness and fatigue at 3-month follow-up [14], many studies have analyzed the impact of mechanisms of injury on persistent post-concussion symptoms while evaluating other risk factors [11, 15-18]. However, sport as the mechanism of injury has an impact on the recovery and return to normal activities.

Only a few studies have attempted to compare the recovery of patients who sustained a sports-related mild TBI with the recovery of patients who sustained other types of injuries [11, 19]. However, most of these studies have focused on high school athletes $[19,20]$, elite collegiate athletes [21, $22]$ or professional athletes $[23,24]$. Understanding the evolution of symptoms depending on the initial mechanism may help to predict recovery or capture particular evolution patterns. The main objective of this study is to compare post-concussion symptoms in patients who sustained a 
sports-related mild TBI to those who sustained non-sportsrelated mild TBI at 7 and 90 days post-mild TBI. Secondary objectives are to compare the prevalence of each Rivermead Post-concussion questionnaire symptom (score of $\geq 2$ ), individually assessed, the prevalence of a total Rivermead Post-concussion questionnaire score $\geq 21$ points (a potential cutoff score), and the prevalence of patients who returned to their normal daily activities at 7 and 90 days post-mild TBI.

\section{Methods}

\section{Study design and setting}

This is a secondary analysis of a multicentre prospective cohort study, which was conducted in seven Canadian Emergency Departments (ED) (five level I trauma centers: the CHU de Québec-Université Laval (Hôpital de l'Enfant-Jésus), the Hôpital du Sacré-Coeur de Montréal, The Ottawa Hospital, Sunnybrook Health Sciences Center (Toronto), Foothills Medical Center (Calgary), one level II trauma center: CISSS de Chaudière-Appalaches and one academic non-trauma center: CHU de Québec-Université Laval (CHUL)), between 04/07/2010 and 30/09/2018. Each research assistant received extensive standardized training to ensure the quality of data collection, which included a group session and personalized field training with supervision by the study coordinator for the study duration.

\section{Population}

Emergency physicians and research assistants identified potential participants in the ED. Patients were included if they: (1) had a documented mild TBI (defined as a Glasgow Coma Scale (GCS) score between 13 and 15 at $30 \mathrm{~min}$ post-injury, and one or more of the following symptoms: loss of consciousness ( $<30 \mathrm{~min}$ ), post-traumatic amnesia $(<24 \mathrm{~h})$, impaired mental state at time of accident (confusion, disorientation and/or transient neurological deficit) [25], (2) had their mild TBI within $24 \mathrm{~h}$ of their ED visit and (3) were aged $\geq 14$ years. Patients who were hospitalized following their ED visit, who were unable to consent or unable to speak French or English were excluded.

\section{Data collection}

Once informed consent was obtained, clinical and sociodemographic data were also collected. Additional information regarding injury mechanism (i.e. motor vehicle collision, assault, and sports), associated injuries, previous hospitalizations, previous head traumas and history of psychiatric disorders was also collected. Three follow-up phone interviews were conducted by a research assistant at 7, 30 and 90 days post-injury. Each of the follow-ups included a question regarding patients' ability to return to each of their usual daily activities (e.g., work, studying, and reading) due to post-concussion symptoms. The replies to the question were coded into a dichotomous variable ("yes" or "no"). The Rivermead Post Concussion Symptoms Questionnaire [26-28], a validated 64-point test commonly used by healthcare professionals to assess post-concussion symptoms, was also administered during those phone interviews to the study participants. This test requires patients to rate the severity of 16 symptoms (affective, physical and cognitive) using a scale ranging from 0 to 4 (0: absent, 1 : same as before, 2 : mild, 3: moderate, and 4: severe), compared to their preinjury status. Thus, a score $\geq 2$ was considered to be consistent with a mild TBI-related problem [26-28]. A high Rivermead Post-concussion questionnaire score indicates a higher number and greater severity of symptoms.

\section{Outcome measures}

To describe and compare the evolution of post-concussion symptoms between patients who sustained sports-related mild TBI and those who sustained non-sports-related mild TBI, the main outcome was defined by the presence of three symptoms or more on the Rivermead Post-concussion questionnaire at 90 days post-injury. This definition is based on the criteria of The International Classification of Diseases, 10th revision (ICD-10) [29]. The secondary outcomes which were all evaluated at 7 and 90 days post-injury were: (1) the prevalence of each symptom of the Rivermead Post-concussion questionnaire, individually assessed, (2) a total score of 21 points or more on the Rivermead Post-concussion questionnaire, a potential cutoff score determined by the study steering committee since none exist in the literature, and (3) the patient's ability to return to their normal daily activities due to post-concussion symptoms, as assessed by patients themselves.

\section{Data analyses}

Descriptive analyses were used for sociodemographic variables. Measured outcomes were computed and compared between the two groups of patients (sports-related mild TBI and non-sports-related mild TBI) using Chi-square tests for normally distributed data and the Fisher's exact test was used for non-normal data. Continuous variables were compared using Student's $T$ tests when the distribution was normal, and the Wilcoxon test was used for non-normal distribution.

A Generalized Poisson Distribution estimating equations (GEEs) regression model with robust standard errors was applied to evaluate the difference of symptoms between the two groups at 7 days, 30 days and 90 days post-injury. For relative risk (RR) calculation, multiple comparison 
adjustments for confidence intervals and $p$ values were used by employing Tukey-Kramer method. The following potentially confounding factors were used to adjust relative risks of post-concussion symptoms: age category (14-24, 25-34, $35-44,45-54,55-64, \geq 65$ years), previous TBI, presence of previous psychiatric disorders, prescribed medication, presence of concomitant injuries and headache. These three last covariates were also used to adjust the relative risks of the impact of mechanism of injury on patients' normal daily activities. Lastly, Inverse Probability-of-Censoring Weights were used to correct for selection bias due to loss to followup at 7, 30 and 90 days [30]. All analyses were performed using the Statistical Analysis System (SAS Institute, Inc., Cary, NC, version 9.4).

This study was approved by the Research Ethics Board of the CHU de Québec_-Université Laval.

\section{Results}

A total of 1727 patients were included in this study. Table 1 shows the sociodemographic and clinical characteristics of our study population. Three hundred and sixty-three patients (21.0\%) sustained a sports-related mild TBI. Both groups had similar gender distribution. Median age was lower for the sports-related mild TBI group. Sports-related mild TBI patients differed significantly from the non-sports-related mild TBI patients in regard to the presence of previous psychiatric disorders, previous TBI, at least one prescribed medication and isolated mild TBI (versus mild TBI with associated injuries). There were also some differences regarding both groups' initial symptoms at time of arrival in the ED. The sports-related mild TBI group differed significantly from the non-sports-related mild TBI cohort in terms of headaches, confusion and loss of consciousness.

Table 2 shows the adjusted relative risks of post-concussion symptoms at 7 and 90 days post-injury. We found no difference between the two groups regarding our primary outcome, the risk of having three symptoms or more on the Rivermead Post-concussion questionnaire at 90 days (RR: 0.8 [95\% CI 0.62-1.08]). There also was no difference regarding the risk of having a total score of 21 points or more at 7 (RR: 1.1 [95\% CI 0.76-1.45]) and 90 days postinjury (RR: 0.5 [95\% CI 0.29-1.00]).

At 7 days, patients from the sports-related mild TBI group were at higher risk of experiencing poor concentration (RR: 1.3 [95\% CI 1.05-1.54]), but at 90 days this difference can no longer be observed. At 90 days post-injury, those patients were at lower risk of fatigue (RR: 0.7 [95\% CI 0.51-0.98]) and dizziness (RR: 0.6 [95\% CI 0.35-0.99]).

The impact of the mechanism of injury (sport versus non-sport) on patients' normal daily activities is shown in Table 3. Patients in the sports-related mild TBI group were at higher risk of non-return to their normal daily activities due to post-concussion symptoms at 7 days post-injury (RR: 1.1 [95\% CI 1.01-1.22]) and more specifically, to their sports activities (RR: 2.2 [95\% CI 1.69-2.94]). However, this was no longer observed 90 days post-injury.

\section{Discussion}

\section{Interpretation of findings}

This study provides new knowledge regarding the evolution of post-concussion symptoms and illustrates potential differences between sports-related mild TBI and other mechanisms of injury. Indeed, returning to their normal daily activities, especially sports, seems to be more difficult at 7 days for patients who sustained a sports-related mild TBI. However, this is no longer observed 90 days post-injury. Most importantly, patients who sustained a sports-related mild TBI appear to be at lower risk of experiencing symptoms such as fatigue and dizziness at 90 days post-injury. Patients from that group also seem to experience fewer symptoms at 90 days post-injury, although this difference was not statistically significant.

\section{Comparison to previous studies}

Our results concur with those of two other studies. Indeed, Sieger et al. found high school athletes aged 13-21 years who suffered sports-related mild TBI (football and soccer) recovered more quickly than others who were involved in a motor vehicle collision [19]. A recent study carried out by Beauchamp et al. among children aged 6-18 years also highlighted that those who sustained sports or recreationalrelated concussions had a better quality of life and were less likely to experience persistent post-concussion symptoms and cognitive impairment. [11] Both studies suggest that these differences could be explained by particular biomechanical characteristics (velocity of impact, distribution of the forces, location and speed) which potentially differ between motor vehicle collision, bicycle accidents or falls and sports injury. As recently shown, brain tissue stresses and strains are related to the impact force of the injury [31]. Thus, some studies suggest that the amount of pathological brain damage influences the neurological dysfunction severity, which could be reflected by the intensity and duration of post-concussion symptoms [32].

However, the literature is inconsistent regarding the impact of mechanism of injury on patient recovery. In fact, a retrospective study by Tator et al. suggests that the mechanism of injury did not predict the number of symptoms and the recovery time [18]. This study included patients who 
Table 1 Clinical and sociodemographic characteristics

\begin{tabular}{|c|c|c|c|}
\hline & $\begin{array}{l}\text { Sports-related mTBI } \\
(n=363)\end{array}$ & $\begin{array}{l}\text { Non-sports-related } \\
\text { mTBI }(n=1364)\end{array}$ & Total $(n=1727)$ \\
\hline & $\%$ & $\%$ & $\%$ \\
\hline \multicolumn{4}{|l|}{ Demographic } \\
\hline Age, median (Q1-Q3) & $17-36$ & $27-59$ & $23-57$ \\
\hline $14-44$ & 81.5 & 50.4 & 57.0 \\
\hline $45-64$ & 12.7 & 32.7 & 28.5 \\
\hline $65-84$ & 5.8 & 15.3 & 13.3 \\
\hline$\geq 85$ & 0.0 & 1.5 & 1.2 \\
\hline Male & 61.7 & 60.4 & 60.7 \\
\hline \multicolumn{4}{|l|}{ Medical history } \\
\hline Previous TBI (including mTBI) & 43.8 & 32.8 & 35.1 \\
\hline Previous psychiatric disorders & 16.5 & 24.8 & 23.1 \\
\hline Depression & 8.5 & 13.8 & 12.7 \\
\hline Generalized anxiety & 4.4 & 86.2 & 5.8 \\
\hline At least 1 prescribed medication ${ }^{\dagger}$ & 39.1 & 60.1 & 55.7 \\
\hline \multicolumn{4}{|l|}{ Mechanism of injury } \\
\hline Motor vehicle collision & - & 19.1 & 15.1 \\
\hline Bicycle accident & - & 16.8 & 13.3 \\
\hline Accident involving pedestrian & - & 40.8 & 32.2 \\
\hline Sports & 100.0 & - & 21.0 \\
\hline Skiing/snowboarding & 24.0 & - & 24.0 \\
\hline Hockey & 14.9 & - & 14.9 \\
\hline Soccer & 9.9 & - & 9.9 \\
\hline Football/rugby & 8.5 & - & 8.5 \\
\hline Ice skating & 7.7 & - & 7.7 \\
\hline Horseback riding & 6.3 & - & 6.3 \\
\hline Cheerleading & 5.5 & - & 5.5 \\
\hline Others & 23.1 & - & 57.6 \\
\hline Other & - & 23.4 & 18.5 \\
\hline Isolated mTBI & 59.4 & 33.5 & 38.9 \\
\hline $\begin{array}{l}\text { Suspected drug/alcohol intoxication } \\
(n=1597)\end{array}$ & 1.5 & 12.9 & 10.5 \\
\hline \multicolumn{4}{|l|}{ Medical assessment in the ED } \\
\hline \multicolumn{4}{|l|}{ GCS at arrival } \\
\hline 15 & 88.2 & 85.3 & 85.9 \\
\hline 14 & 11.3 & 13.6 & 13.1 \\
\hline 13 & 0.6 & 1.2 & 1.0 \\
\hline Loss of consciousness & 45.6 & 52.2 & 50.8 \\
\hline Headache & 78.6 & 64.9 & 67.9 \\
\hline Confusion & 63.5 & 54.3 & 56.2 \\
\hline Retrograde amnesia & 28.1 & 25.0 & 25.7 \\
\hline Anterograde amnesia & 44.4 & 44.9 & 58.2 \\
\hline Vomiting $\geq 2$ episodes & 8.3 & 7.0 & 7.3 \\
\hline
\end{tabular}

${ }^{\dagger}$ Patients taking at least one prescribed medication were referred to one neurosurgeon with a specific interest in post-concussion symptoms. Even if the referral criteria are unknown, these patients were most likely suffering from more complicated and persistent post-concussion symptoms, thus affecting the generalizability of the study. 
Table 2 Impact of injury mechanism (sport vs non-sport) on post-concussion symptoms at 7 days and 90 days postmild TBI

\begin{tabular}{|c|c|c|}
\hline & $\begin{array}{l}7 \text { days post-injury }(n=1476)^{*} \\
\text { Adjusted } \mathrm{RR}^{\mathrm{F}}(95 \% \mathrm{CI})\end{array}$ & $\begin{array}{l}90 \text { days post-injury }(n=1426)^{*} \\
\text { Adjusted } \mathrm{RR}^{\mathrm{T}}(95 \% \mathrm{CI})\end{array}$ \\
\hline \multicolumn{3}{|c|}{ Total Rivermead Post-concussion questionnaire score } \\
\hline 3 symptoms & $1.1(0.9-1.2)$ & $0.8(0.6-1.1)$ \\
\hline Score $\geq 21$ & $1.1(0.8-1.5)$ & $0.5(0.3-1.0)$ \\
\hline \multicolumn{3}{|c|}{ Rivermead Post-concussion questionnaire symptoms } \\
\hline \multicolumn{3}{|l|}{ Physical } \\
\hline Headaches & $1.1(0.96-1.3)$ & $0.7(0.5-1.1)$ \\
\hline Feeling of dizziness & $1.1(0.9-1.3)$ & $0.6(0.4-0.99)$ \\
\hline Light sensitivity & $1.3(0.98-1.7)$ & $0.9(0.5-1.5)$ \\
\hline Noise sensitivity & $1.3(0.99-1.7)$ & $0.8(0.5-1.3)$ \\
\hline Nausea & $1.1(0.8-1.7)$ & $0.7(0.3-1.7)$ \\
\hline Sleep disturbance & $1.1(0.8-1.4)$ & $0.7(0.5-1.2)$ \\
\hline Blurred vision & $1.1(0.7-1.7)$ & $0.7(0.4-1.4)$ \\
\hline Double vision & $1.2(0.5-3.0)$ & $0.8(0.2-2.7)$ \\
\hline Fatigue & $1.03(0.9-1.2)$ & $0.7(0.5-0.98)$ \\
\hline \multicolumn{3}{|l|}{ Cognitive } \\
\hline Forgetfulness & $0.98(0.8-1.3)$ & $0.8(0.6-1.2)$ \\
\hline Taking longer to think & $1.1(0.9-1.4)$ & $0.7(0.5-1.1)$ \\
\hline Poor concentration & $1.3(1.1-1.5)$ & $0.9(0.6-1.2)$ \\
\hline \multicolumn{3}{|l|}{ Affective } \\
\hline Feeling depressed & $1.03(0.7-1.5)$ & $0.7(0.4-1.2)$ \\
\hline Being irritable & $1.2(0.9-1.5)$ & $0.6(0.4-1.0)$ \\
\hline Feeling frustrated & $1.1(0.9-1.5)$ & $0.7(0.4-1.1)$ \\
\hline Restlessness & $0.96(0.5-1.8)$ & $0.4(0.1-1.2)$ \\
\hline
\end{tabular}

Statistical significant values are indiacted in bold

$C I$ confidence interval, $R R$ relative risks

*Due to missing data, the number of patients does not always add up to the total number presented in Fig. 1 ${ }^{\mathrm{F}}$ Compares patients sustaining sports-related mTBI with those sustaining non-sports-related mTBI (reference). RR were adjusted for age (14-24, 25-34, 35-44, 45-54, 55-64, $\geq 65$ years), previous TBI, isolated $\mathrm{mTBI}$, prescribed medication, previous psychiatric disorders and headache

\section{Strengths and limitations}

Our study has limitations. First, the exposure factor (mechanism of injury) could not be controlled. Therefore, this kind of research question cannot be answered with a prior randomization, thus forcing the use of a prospective observational study design. This may explain why the sample size of the sports-related mild TBI cohort were just under a third of the non-sports-related mild TBI cohort. In the literature, more than half of the mild TBI are usually due to sports injury [4]. This discrepancy may be caused by the fact that our cohort includes older patients. In addition, sports-related mild TBI patients may be more likely to be managed by sports team physiotherapists or doctors instead of going to the ED. Furthermore, groups differed significantly in some of their initial characteristics, especially age, which had a non-linear relation with our main study outcome. The groups were also very different for prescribed medications which suggests a difference in baseline health. However, statistical adjustments were performed for all potentially confounding factors. Data regarding pre-mild TBI level of physical activity and the recovery process was not available. Nonetheless, we can probably infer patients that sustained sports-related mild TBI were more active. This lack of information limits our capacity to interpret the differences observed. Lastly, since 3 months is often the minimal duration time to considerer a symptom as persistent [33], it would have been interesting to extend the follow-up duration to have a more long-term vision of the patients' clinical course and thus, see if differences in the recovery of both groups remained or even increased.

However, our study had several strengths such as a very large sample of non-hospitalized mild TBI patients. All data were collected on a prospective basis through phone interviews conducted by experienced research assistants, which brought better internal validity to the study than self-administered questionnaires. The multicenter nature of our study and the fact that patients from different levels 
Fig. 1 Flow chart

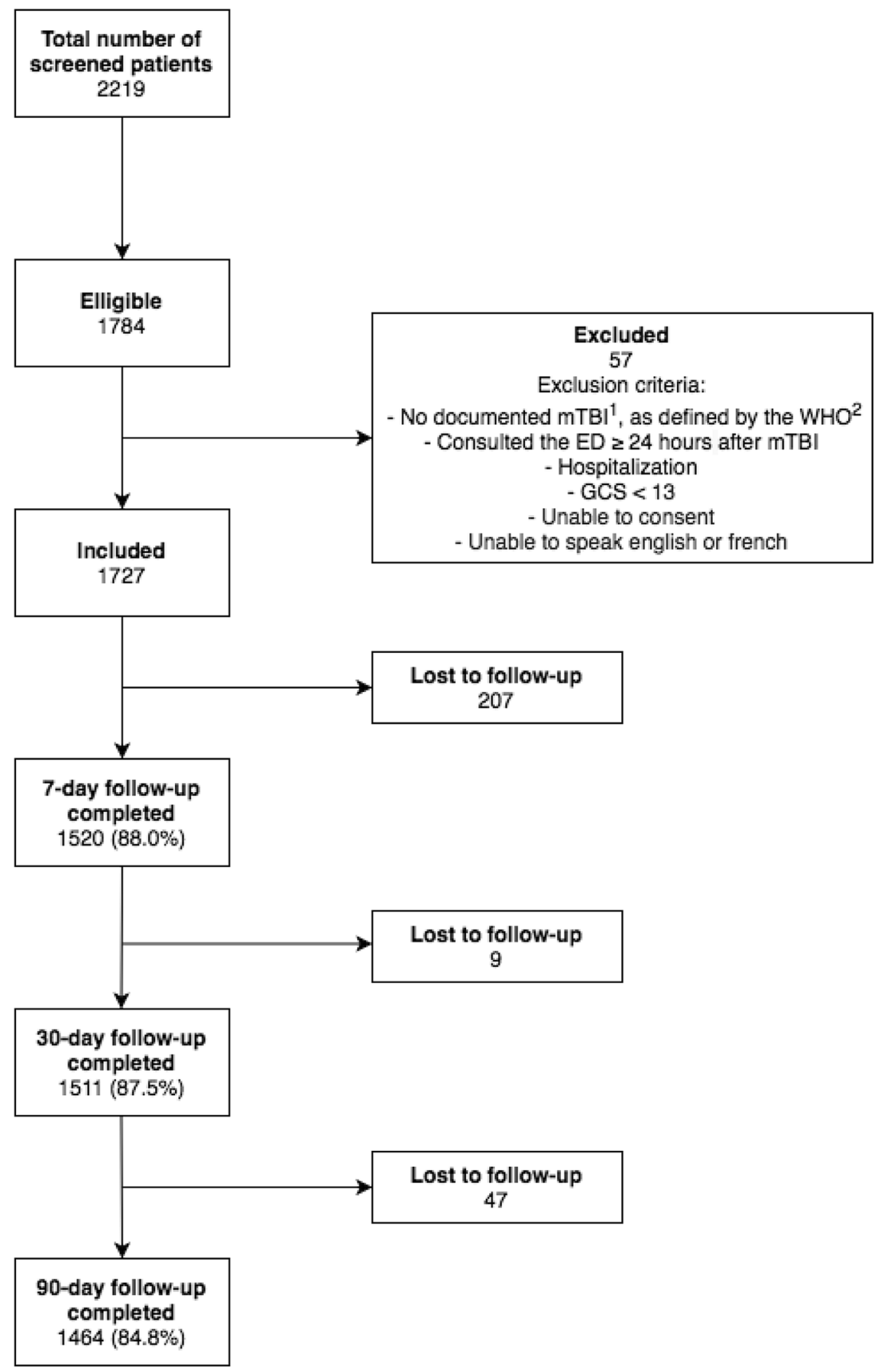

${ }^{1}$ Mild traumatic brain injury

${ }^{2}$ Worlds Health Organization

of trauma centers across Canada ensured that our participants are representative of mild TBI patients seen in the ED.

\section{Clinical implications}

Recent studies suggest that early controlled sub-symptom threshold aerobic exercise might be more beneficial than rest in mild TBI recovery [10, 34-39]. Physically active individuals could somehow be protected from a poor outcome and recover faster as they are probably more inclined to progressively return to physical activities during their rehabilitation. Their medical follow-up may be more comprehensive and they might also enjoy a better state of physical and mental health [40]. Therefore, being physically active during 
Table 3 Impact of injury mechanism (sport vs non-sport) on patient's normal activities at 7 days and 90 days post-injury

\begin{tabular}{|c|c|c|}
\hline & $\begin{array}{l}7 \text { days post-injury }(n=622)^{*} \\
\text { Adjusted } \mathrm{RR}^{\mathrm{F}}(95 \% \mathrm{CI})\end{array}$ & $\begin{array}{l}90 \text { days post-injury }(n=599)^{*} \\
\text { Adjusted RR }(95 \% \mathrm{CI})\end{array}$ \\
\hline $\begin{array}{l}\text { Did not return to normal activities } \\
\text { due to } \mathrm{mTBI}^{\dagger}\end{array}$ & $1.1(1.01-1.2)$ & $1.1(0.9-1.4)$ \\
\hline \multicolumn{3}{|l|}{ Altered activities } \\
\hline Sports & $2.2(1.7-2.9)$ & $0.9(0.4-2.2)$ \\
\hline Reading & $1.6(0.98-2.7)$ & $0.6(0.1-2.9)$ \\
\hline Work on the computer & $1.3(0.8-2.0)$ & $0.4(0.1-2.5)$ \\
\hline Social activities & $0.7(0.3-1.6)$ & $0.2(0.01-3.7)$ \\
\hline Car driving & $1.04(0.6-1.9)$ & $0.2(0.01-3.8)$ \\
\hline Television & $1.5(0.95-2.5)$ & $0.8(0.1-4.8)$ \\
\hline Others & $0.7(0.2-2.6)$ & $0.5(0.03-9.9)$ \\
\hline
\end{tabular}

Statistical significant values are indiacted in bold

$C I$ confidence interval, $R R$ relative risks

*Due to missing data, the number of patients does not always add up to the total number presented in Fig. 1

${ }^{\mathrm{F}}$ Compares patients sustaining sports-related mTBI with those sustaining non-sports-related mTBI (reference). RR were adjusted for prescribed medication, isolated TCC and headache

${ }^{\dagger}$ Patients who did not return to their normal activities due to the mTBI (patient-reported outcome) rehabilitation, coupled with a more structured follow-up may prevent, or at least lessen the post-concussion symptoms. Of course, further research is needed to support this, and to further improve treatment recommendations for mild TBI management.

\section{Research implications}

Since information regarding the patients' rehabilitation process have not been collected, more research is needed to better understand the underlying causes of the differences observed to improve post-ED mild TBI patient management.

\section{Conclusion}

This study identified potential differences in the clinical course of mild TBI patients depending on the mechanism of injury. Indeed, patients who sustained sports-related injury seemed to experience less fatigue and dizziness 90 days post-injury. These differences should be considered when planning post-ED care, as clinicians should be mindful that non-sports-related mild TBI patients may experience more post-concussion symptoms and that the level of physical activity may influence the patient's rehabilitation.

Acknowledgements We are deeply indebted to all the patients who participated in this study and gratefully acknowledge the emergency physicians at the study sites who recruited the patients and the emergency medicine residents who helped in this process. We acknowledge the following members of our research team: Quebec site-Marilyne Dufresne, Martin Roy, Catherine Bédard and Suzy Lavoie; Lévis siteLise Lavoie and Josée Jolicoeur; Trois-Rivières site-Émilie Gouin and Annie Cossette; Montreal site-Chantal Lanthier, Tanya Leduc and Catherine Perreault-Légaré; Ottawa site-Connor Sheehan.

Funding This study was funded by the Canadian Institutes of Health Research. FB was recipient of a scholarship from the Faculté de Médecine de l'Université Laval.

\section{Compliance with ethical standards}

Conflict of interest The authors declare that they have no conflict of interest statement.

\section{References}

1. Taylor CA, Bell JM, Breiding MJ, Xu L. Traumatic brain injuryrelated emergency department visits, hospitalizations, and deaths-United States, 2007 and 2013. MMWR Surveill Summ. 2017;66(9):1-16 (Epub 2017/03/17).

2. Cassidy JD, Carroll LJ, Peloso PM, Borg J, von Holst H, Holm L, Kraus J, Coronado VG, WHO Collaborating Centre Task Force on Mild Traumatic Brain Injury. Incidence, risk factors and prevention of mild traumatic brain injury: results of the WHO Collaborating Centre Task Force on Mild Traumatic Brain Injury. J Rehabil Med. 2004;(43 Suppl):28-60. https://doi.org/10.1080/16501 960410023732.

3. Ryu WH, Feinstein A, Colantonio A, Streiner DL, Dawson DR. Early identification and incidence of mild TBI in Ontario. Can J Neurol Sci. 2009;36(4):429-35 (Epub 2009/08/05).

4. Gordon KE, Dooley JM, Wood EP. Descriptive epidemiology of concussion. Pediatr Neurol. 2006;34(5):376-8 (Epub 2006/05/02). 
5. McCrory P, Meeuwisse W, Dvorak J, et al. Consensus statement on concussion in sport-the 5(th) international conference on concussion in sport held in Berlin, October 2016. Br J Sports Med. 2017;51(11):838-47 (Epub 2017/04/28).

6. Langlois JA, Rutland-Brown W, Wald MM. The epidemiology and impact of traumatic brain injury: a brief overview. J Head Trauma Rehabil. 2006;21(5):375-8 (Epub 2006/09/20).

7. Banks RE, Dominguez DC. Sports-related concussion: neurometabolic aspects. Semin Speech Lang. 2019;40:333-43 (Epub 2019/02/15).

8. Mannix R, Bachur R. Diagnosis of concussion in the pediatric emergency department. Semin Pediatr Neurol. 2019;30:35-9 (Epub 2019/06/27).

9. Mahooti N. Sports-related concussion: acute management and chronic postconcussive issues. Child Adolesc Psychiatr Clin N Am. 2018;27(1):93-108 (Epub 2017/11/22).

10. Schneider KJ, Leddy JJ, Guskiewicz KM, et al. Rest and treatment/rehabilitation following sport-related concussion: a systematic review. Br J Sports Med. 2017;51(12):930-4 (Epub 2017/03/28).

11. Beauchamp MH, Tang K, Yeates KO, et al. Predicting wellness after pediatric concussion. J Int Neuropsychol Soc. 2019;25(4):375-89 (Epub 2019/05/03).

12. Iverson GL, Gardner AJ, Terry DP, et al. Predictors of clinical recovery from concussion: a systematic review. Br J Sports Med. 2017;51(12):941-8 (Epub 2017/06/02).

13. Ponsford J, Nguyen S, Downing M, et al. Factors associated with persistent post-concussion symptoms following mild traumatic brain injury in adults. J Rehabil Med. 2019;51(1):32-9 (Epub 2018/11/15)

14. Ponsford J, Willmott C, Rothwell A, et al. Factors influencing outcome following mild traumatic brain injury in adults. J Int Neuropsychol Soc. 2000;6(5):568-79 (Epub 2000/08/10).

15. Nelson LD, Furger RE, Ranson J, et al. Acute clinical predictors of symptom recovery in emergency department patients with uncomplicated mild traumatic brain injury or non-traumatic brain injuries. J Neurotrauma. 2018;35(2):249-59 (Epub 2017/10/12).

16. Fehr SD, Nelson LD, Scharer KR, et al. Risk factors for prolonged symptoms of mild traumatic brain injury: a pediatric sports concussion clinic cohort. Clin J Sport Med. 2019;29(1):11-7 (Epub 2017/10/31).

17. Kerr ZY, Collins CL, Mihalik JP, et al. Impact locations and concussion outcomes in high school football player-to-player collisions. Pediatrics. 2014;134(3):489-96 (Epub 2014/08/13).

18. Tator $\mathrm{CH}$, Davis HS, Dufort PA, et al. Postconcussion syndrome: demographics and predictors in 221 patients. J Neurosurg. 2016;125(5):1206-16 (Epub 2016/11/02).

19. Seiger A, Goldwater E, Deibert E. Does mechanism of injury play a role in recovery from concussion? J Head Trauma Rehabil. 2015;30(3):E52-6 (Epub 2014/06/06).

20. Kerr ZY, Zuckerman SL, Wasserman EB, et al. Factors associated with post-concussion syndrome in high school student-athletes. J Sci Med Sport. 2018;21(5):447-52 (Epub 2017/09/25).

21. Kerr ZY, Zuckerman SL, Wasserman EB, et al. Concussion symptoms and return to play time in youth, high school, and College American Football Athletes. JAMA Pediatr. 2016;170(7):647-53 (Epub 2016/05/03).

22. Vargas G, Rabinowitz A, Meyer J, Arnett PA. Predictors and prevalence of postconcussion depression symptoms in collegiate athletes. J Athl Train. 2015;50(3):250-5 (Epub 2015/02/03).

23. Cookinham B, Swank C. Concussion history and career status influence performance on baseline assessments in elite football players. Arch Clin Neuropsychol. 2019;35:257-64 (Epub 2019/03/31).

24. Didehbani N, Munro Cullum C, Mansinghani S, Conover H, Hart $\mathrm{J}$ Jr. Depressive symptoms and concussions in aging retired NFL players. Arch Clin Neuropsychol. 2013;28(5):418-24 (Epub 2013/05/07).

25. Carroll LJ, Cassidy JD, Holm L, Kraus J, Coronado VG, WHO Collaborating Centre Task Force on Mild Traumatic Brain Injury. Methodological issues and research recommendations for mild traumatic brain injury: the WHO Collaborating Centre Task Force on Mild Traumatic Brain Injury. J Rehabil Med. 2004;(43 Suppl):113-25. https://doi.org/10.1080/16501960410023877.

26. King NS, Crawford S, Wenden FJ, Moss NE, Wade DT. The Rivermead Post Concussion Symptoms Questionnaire: a measure of symptoms commonly experienced after head injury and its reliability. J Neurol. 1995;242(9):587-92 (Epub 1995/09/01).

27. Eyres S, Carey A, Gilworth G, Neumann V, Tennant A. Construct validity and reliability of the Rivermead Post-Concussion Symptoms Questionnaire. Clin Rehabil. 2005;19(8):878-87 (Epub 2005/12/06).

28. Potter S, Leigh E, Wade D, Fleminger S. The Rivermead Post Concussion Symptoms Questionnaire: a confirmatory factor analysis. J Neurol. 2006;253(12):1603-14 (Epub 2006/10/26).

29. Lagarde E, Salmi LR, Holm LW, et al. Association of symptoms following mild traumatic brain injury with posttraumatic stress disorder vs. postconcussion syndrome. JAMA Psychiatry. 2014;71(9):1032-40 (Epub 2014/07/17).

30. Howe CJ, Cole SR, Lau B, Napravnik S, Eron JJ Jr. Selection bias due to loss to follow up in cohort studies. Epidemiology. 2016;27(1):91-7 (Epub 2015/10/21).

31. Hsieh TH, Kang JW, Lai JH, et al. Relationship of mechanical impact magnitude to neurologic dysfunction severity in a rat traumatic brain injury model. PLoS ONE. 2017;12(5):e0178186 (Epub 2017/05/30).

32. Post A, Kendall M, Koncan D, et al. Characterization of persistent concussive syndrome using injury reconstruction and finite element modelling. J Mech Behav Biomed Mater. 2015;41:325-35 (Epub 2014/08/27).

33. Marshall SBM, McCullagh S, Berrigan L, Fischer L, Ouchterlony D, Rockwell C, Velikonja D, et al. Guideline for concussion/mild traumatic brain injury and persistent symptoms. 3rd ed. Ontario: Ontario Neurotrauma Foundation; 2018.

34. Kurowski BG, Hugentobler J, Quatman-Yates C, et al. Aerobic exercise for adolescents with prolonged symptoms after mild traumatic brain injury: an exploratory randomized clinical trial. J Head Trauma Rehabil. 2017;32(2):79-89 (Epub 2016/04/28).

35. Tan CO, Meehan WP 3rd, Iverson GL, Taylor JA. Cerebrovascular regulation, exercise, and mild traumatic brain injury. Neurology. 2014;83(18):1665-72 (Epub 2014/10/03).

36. Howell DR, Taylor JA, Tan CO, Orr R, Meehan WP 3rd. The role of aerobic exercise in reducing persistent sport-related concussion symptoms. Med Sci Sports Exerc. 2019;51(4):647-52 (Epub 2018/10/31).

37. Leddy JJ, Wilber CG, Willer BS. Active recovery from concussion. Curr Opin Neurol. 2018;31(6):681-6 (Epub 2018/11/02).

38. Henke RD, Kettner SM, Jensen SM, Greife ACK, Durall CJ. Does early low-intensity aerobic exercise hasten recovery in adolescents with sport-related concussion? J Sport Rehabil. 2019;18:1-5. https://doi.org/10.1123/jsr.2019-0070.

39. Hattrup N, Gray H, Krumholtz M, Valovich McLeod TC. Early controlled exercise and timing of treatment following concussion: a critically appraised topic. J Sport Rehabil. 2019;18:1-7. https:// doi.org/10.1123/jsr.2019-0187.

40. Paluska SA, Schwenk TL. Physical activity and mental health. Sports Medicine. 2000;29(3):167-80. 